\title{
A beetroot juice shot is a significant and convenient source of bioaccessible antioxidants
}

\author{
Peter C. Wootton-Beard and Lisa Ryan \\ Functional Food Centre, Oxford Brookes University, Gipsy Lane, Oxford OX3 OBP, UK
}

The most recent national diet and nutrition survey (NDNS) revealed that two thirds of the UK population still do not consume five portions of fruit and vegetables per day ${ }^{(1)}$. Innovative and convenient new products are required to help inspire people to improve their diet. Beetroot juice is rich in antioxidants, particularly polyphenolic compounds ${ }^{(2)}$. The total antioxidant capacity (TAC) and total polyphenol (TP) content of a beetroot juice shot $(70 \mathrm{ml})$ was examined following in vitro digestion. TAC was assessed using the ferric reducing antioxidant power (FRAP) assay and TP content was measured using the Folin Ciocalteu (FC) method (measured as gallic acid equivalents (GAE)) before and after an in vitro digestion procedure with simulated gastric and duodenal phases.

\begin{tabular}{|c|c|c|c|c|c|c|c|c|}
\hline \multirow[b]{2}{*}{ Product } & \multicolumn{2}{|c|}{ FRAP $(\mu \mathrm{mol})$} & \multicolumn{2}{|c|}{ FRAP post digestion $(\mu \mathrm{mol})$} & \multicolumn{2}{|c|}{ TP (mg GAE) } & \multicolumn{2}{|c|}{ TP post digestion (mg GAE) } \\
\hline & $70 \mathrm{ml}$ & SE & $70 \mathrm{ml}$ & $\mathrm{SE}$ & $70 \mathrm{ml}$ & $\mathrm{SE}$ & $70 \mathrm{ml}$ & SE \\
\hline James White beetroot shot & 697.9 & 1.6 & $1740.3 \dagger$ & 21.1 & 68.4 & 0.3 & $223.2 \dagger$ & 5.4 \\
\hline James White beetroot juice* & 584.8 & 5.9 & 850.6 & 23.5 & 101.5 & 2.9 & 106.9 & 1.3 \\
\hline V8 Vegetable juice* & 180.1 & 3.4 & 244.2 & 15.6 & 43.2 & 1.1 & 74.7 & 0.5 \\
\hline V8 Fruit and vegetable juice* & 144.8 & 3.4 & 349.0 & 10.3 & 37.6 & 1.3 & 76.8 & 0.5 \\
\hline Del Monte tomato juice* & 154.1 & 2.8 & 215.0 & 3.6 & 48.7 & 1.4 & 78.4 & 0.9 \\
\hline Eden organic carrot juice* & 107.3 & 0.8 & 191.9 & 1.5 & 33.2 & 0.5 & 71.6 & 0.3 \\
\hline
\end{tabular}

* Published values are given for comparative purposes only, and are not included in the statistical analysis for this experiment. Results are expressed as mean (SE) of three experiments in triplicate. 'Post digestion' refers to TAC following the duodenal phase of the in vitro digestion procedure. $\dagger$ Significantly increased compared with the juice prior to digestion, $P<0.01$.

The beetroot shot had a high TAC $(697.9 \mu \mathrm{mol} / 70 \mathrm{ml})$ and TP content $(68.4 \mathrm{mg}$ GAE/70 ml). FRAP values increased significantly $(P<0.01)$ after the gastric phase $(2361.2 \mu \mathrm{mol} / 70 \mathrm{ml})$ and remained significantly higher $(P<0.01)$ following the duodenal phase $(1740.3 \mu \mathrm{mol} / 70 \mathrm{ml})$. TP content also increased significantly $(P<0.01)$ following the gastric phase $(341.6 \mathrm{mg} \mathrm{GAE} / 70 \mathrm{ml})$ and remained significantly higher $(P<0.01)$ following the duodenal phase $(223.2 \mathrm{mg}$ GAE/ $70 \mathrm{ml})$. The beetroot shot delivers a high amount of bioaccessible antioxidants in comparison with other vegetable juices per $70 \mathrm{ml}$ serving. As a result it may be considered as a cost effective and convenient method of increasing antioxidant status in the general public. Human intervention studies are now required to determine the effects of the beetroot shot in vivo.

1. Bates B (2010) National Diet and Nutrition Survey pp. 1-53 [B. Bates, A. Lennox \& G. Swan editors]. London: Food Standards Agency.

2. Wootton-Beard PC, Moran A \& Ryan L (2011) Food Res Int 44, 217-224. 